\title{
Educação fiscal: premissa para melhor percepção da questão tributária*
}

\author{
Denize Grzybovski** \\ Tatiana Gaertner Hahn***
}

S UMÁRIO : 1. Introdução; 2 . Estado e gestão dos recursos públicos; 3 . Administração pública e seus fundamentos; 4. A tributação no Brasil e a representação social do tributo; 5. A educação fiscal no Brasil; 6. Procedimentos metodológicos; 7. Resultados da pesquisa; 8. Análise dos resultados; 9. Considerações finais.

S UM MARY: 1. Introduction; 2. State and management of public frends; 3. Public administration and its framework; 4. Taxation in Brazil and tax social representation; 5. Fiscal education in Brazil, 6. Methodological procedures; 7. Research results; 8 . Analysis of the results; 9. Final remarks.

Palavras-chave: tributo; arrecadação; contribuinte; educação fiscal.

KEY WORDS: taxes; revenue; tax payer; fiscal education.

Tributo é elemento inerente à existência do Estado, necessário à organização da sociedade e ponto nevrálgico da relação Estado-cidadão. Este artigo explora os conceitos teóricos da educação fiscal e da administração pública para, por meio de dados empíricos, discutir alternativas para aproximar os interesses do Estado aos do cidadão. Os sujeitos investigados são caracterizados como administradores-empresários. Os resultados revelam falta de sintonia entre o que o cidadão espera e está disposto a contribuir com aquilo que o governo oferece e exige em tributos. Implantar programas de educação fiscal é uma alternativa

\footnotetext{
* Artigo recebido em nov. 2004 e aceito em mar. 2006.

** Bacharel em administração, mestre em organização e administração de empresas pela Universidad del Museo Social Argentino (Umsa), Argentina, doutoranda em administração na Universidade Federal de Lavras e professora de teorias organizacionais na Universidade de Passo Fundo. Endereço: Caixa Postal 611/631, BR 285, km 171 — Bairro São José - CEP 99001-970, Passo Fundo, RS, Brasil. E-mail: gdenize@upf.br.

*** Bacharel em administração pela Universidade de Passo Fundo (UPF) e técnica da Secretaria da Receita Federal. Endereço: Rua Paissandu, 753 - Centro - CEP 99010-100, Passo Fundo, RS, Brasil. E-mail: tatiana.hahn@receita.fazenda.gov.br.
} 
que possibilita ao contribuinte conhecer o Estado e sua estrutura, a função socioeconômica dos tributos, o valor da arrecadação tributária, além de incentivar o acompanhamento da aplicação dos recursos arrecadados.

\section{Fiscal education: premise for a better perception of the tax issue}

Taxes are inherent to the state's existence, necessary to the organization of society and a tender spot in the state-citizen relationship. This article explores theoretical concepts of fiscal education and public administration and uses empirical data in order to discuss ways to bring the State's and the citizens' interests closer. The investigated subjects were entrepreneur-administrators. The conclusion reveals a lack of synchronism between what the citizen expects and is willing to pay and what the government offers and demands in terms taxes. The implementation of fiscal education programs allows the citizen to know and understand the state and its structure, the socioeconomic function of taxes, and the value of tax revenue, stimulating him to check how his taxes are put into use.

\section{Introdução}

Desde o início do século XX, as transformações tecnológicas e econômicas têm provocado reflexões sobre o papel do Estado. Atualmente, o desafio é articular um novo modelo de desenvolvimento que traga à sociedade perspectivas de relações Estado-cidadão mais equilibradas, administração pública menos burocrática, tendo como escopo conceitos de descentralização e eficiência, voltada para o controle dos resultados e mais próxima do cidadão. Para enfrentar os desafios inerentes a essa proposta, pressupõe-se a modernização do Estado com a incorporação de novos conhecimentos em torno de questões consideradas "corretas".

Por entender que os impostos pagos não são aplicados adequadamente e a ela não retornam em forma de benefícios, para parte da sociedade as obrigações tributárias são fontes de conflito e de insatisfação. A sociedade brasileira, em especial, não acredita que o produto arrecadado está sendo revertido em melhoria das condições de vida da população (Rua, 2000). Essa visão, aliada à perspectiva de obter maiores lucros pessoais, fortalece a mentalidade de sonegação de impostos.

No Brasil, talvez pela elevada carga tributária, pelo baixo nível de retorno à sociedade e pelos casos de corrupção, prepondera a cultura de nãopagamento de tributos. Uma das pressuposições envolve o desconhecimento da importância do Estado como regulador da vida em sociedade e dos tributos como mantenedores da "máquina pública". 
Neste contexto se insere o problema relativo ao grau de percepção dos empresários a respeito da importância do recolhimento espontâneo dos tributos e da sua aplicação, visando promover programas que reduzam a sonegação e a evasão fiscal. O tema educação fiscal visa a conscientização da sociedade quanto à necessidade de financiamento do Estado através da arrecadação de tributos, o dever do cidadão contribuinte de pagá-los e o direito de acompanhar sua aplicação (Brasil, Receita Federal, 2003). O objetivo é sensibilizar as pessoas sobre o valor socioeconômico do tributo, a importância do cumprimento dos deveres tributários e o direito de acompanhamento das ações públicas na aplicação dos recursos.

Com o propósito de disseminar a idéia de educação fiscal, realizou-se um estudo empírico com um grupo selecionado de empresários. Os resultados apontam um distanciamento nas relações Estado-cidadão, o qual pode ser reduzido por programas de educação fiscal.

\section{Estado e gestão dos recursos públicos}

A origem do Estado pode ser explicada pela vertente de Aristóteles, Hegel e Marx, que o compreendem como conseqüência de um processo histórico de grupos ou classes com maior poder, que o institucionalizaram, estabeleceram a ordem na sociedade e garantiram para si o excedente econômico (Pref, 2002).

A definição clássica considera Estado o conjunto de três elementos indissociáveis (povo, território e governo soberano) (Meirelles, 1995), que existe quando a sociedade de um território tem o poder de organizar-se, independente de qualquer outro Estado, impondo ordem jurídica soberana a todos que estiverem em seu território (Gusmão, 1986). A esses elementos, Dallari (1998) acrescenta a finalidade de buscar o bem comum do povo como unidade que surge do desejo de realização de fins particulares.

Sendo assim, nos termos da Carta Magna, o Brasil é um Estado federal caracterizado pela repartição de competências. A organização político-administrativa compreende a União, os estados, o Distrito Federal e os municípios, todos autônomos entre si. A atividade política decorre do fato de eles se auto-organizarem, regendo-se por constituições e leis próprias, podendo escolher seus governantes e legisladores de acordo com os princípios constitucionais (Meirelles, 1995).

No que tange aos objetivos fundamentais do Estado brasileiro, o art. $3^{\mathrm{o}}$ da Constituição Federal de 1988 estabelece a construção de uma sociedade livre, justa e solidária, a garantia do desenvolvimento nacional, a redução das desigualdades sociais e regionais e a promoção do bem de todos, sem preconceitos ou discriminação. 
Esses objetivos estatais são manifestados através de três poderes independentes e harmônicos entre si. Assim, a atividade administrativa do Estado deve seguir os termos da lei e da moralidade administrativa, de bens, interesses e serviços públicos visando o bem comum, compreendendo os poderes de guarda, conservação e aprimoramento dos bens e interesses a ela submetidos (Gasparini, 1995).

Para atender as necessidades públicas (saúde, educação, habitação, saneamento, transportes, segurança, urbanismo, justiça e outras), o Estado precisa obter, administrar e empregar meios patrimoniais que lhe possibilitem o desempenho das outras atividades que se referem à realização de seus fins (Sousa, 1975): exercer a gestão financeira.

A atividade financeira do Estado desenvolve-se em termos de receita (obtenção de recursos patrimoniais), de gestão (administração e conservação do patrimônio público) e de despesa (emprego de recursos patrimoniais para a realização dos fins públicos). À medida que os recursos produtivos se expandem e se aperfeiçoam, a atividade financeira pública fica ainda mais complexa. Da mesma forma que os recursos produtivos se expandem e se aperfeiçoam, também o fazem os desejos e as necessidades humanas (Rossetti, 1994). Como conseqüência têm-se melhores condições de vida, como o aumento na perspectiva de longevidade.

Para a eficiência das demandas sociais, os entes federados contam com autonomia política, administrativa e financeira, além das competências específicas previstas na $\mathrm{CF} / 88$ e dos recursos financeiros arrecadados através dos tributos. O desenvolvimento dessas atividades está no âmbito da gestão da administração pública, que corresponde a um conjunto de operações com o objetivo de alcançar os fins próprios do Estado e desenvolve-se por meio de órgãos específicos de cada esfera de governo (Meirelles, 1995).

No art. 165 da CF/88 encontram-se os instrumentos de planejamento e orçamento público de médio e longo prazos, de forma hierarquizada, que são estabelecidos por leis de iniciativa do Poder Executivo. Através do instrumento de gestão "orçamento" o Estado prevê as receitas e fixa as despesas públicas aos três poderes. No que tange à gestão desses recursos, as despesas são cobertas com o produto da arrecadação dos tributos e outras fontes de receitas (empréstimos, operações de crédito, alienações), estimadas com base na arrecadação de impostos.

O conjunto dessas ações resulta no gerenciamento dos recursos públicos para a satisfação da comunidade, que contribuiu arrecadando os tributos devidos. Esses atos públicos formam a área de administração pública.

\section{Administração pública e seus fundamentos}

Por administração pública entende-se o ato de se realizarem serviços para o bem-estar coletivo e o atendimento dos interesses e anseios da sociedade por 
intermédio das ações do Estado. Isso envolve os órgãos da administração direta e indireta, bem como as empresas privadas a quem o Estado delega a consecução de determinados serviços públicos (Meirelles, 1995).

Para oferecer serviços públicos satisfatórios aos cidadãos torna-se imprescindível o gerenciamento dos recursos públicos de forma a aplicá-los em atividades prioritárias para a comunidade. A conscientização do papel da administração pública ganhou maior relevância com a Lei de Responsabilidade Fiscal, que requer a participação da comunidade nas decisões do orçamento anual. A legislação abriu espaços para o contribuinte cobrar a aplicação dos recursos arrecadados pelo Estado e conhecer o plano de governo. Para tanto, o cidadão deve estar consciente de suas necessidades sociais, seus direitos e deveres, o que pressupõe a ampliação da compreensão do conceito de administração pública (Rua, 2000).

Há significativos avanços na conscientização do cidadão e na ampliação do exercício da cidadania. Alguns estados e municípios realizam consultas populares para a elaboração do orçamento-programa, possibilitando a discussão das prioridades da ação governamental (Bebiano, 2001). Tais experiências, que tendem a uma gestão pública moderna e democrática, são iniciativas que inserem o cidadão na gestão dos recursos públicos, dando-lhe força e legitimidade cidadã.

O intercâmbio Estado-cidadão altera as relações de poder e se estende aos responsáveis pelo planejamento das políticas públicas plurianuais (Bebiano, 2001) que antecedem e orientam a elaboração da proposta orçamentária anual.

\section{A tributação no Brasil e a representação social do tributo}

Uma vez compreendidos o funcionamento do Estado e a gestão dos recursos públicos, faz-se necessário conhecer os aspectos específicos sobre tributação com vistas à discussão de alternativas para aproximar os interesses do Estado (recolhimento espontâneo dos tributos) dos interesses do cidadão (acompanhamento da aplicação dos recursos arrecadados).

No Brasil, a história dos tributos tem início em 1500, quando os portugueses aqui chegaram e se apossaram das terras e de todas as riquezas que encontraram, transformando-as em monopólio do rei de Portugal. A primeira organização tributária surgiu com as capitanias hereditárias, em 1534, quando Portugal nomeou os primeiros funcionários tributários que tinham a seu encargo a arrecadação de impostos, tributos e foros devidos à Fazenda Real. Os do- 
natários das capitanias eram obrigados a pagar ao rei de Portugal uma parte de tudo o que produziam: açúcar, fumo, aguardente etc. (Bordin, 2002).

As exigências tributárias da metrópole sobre a colônia aumentaram significativamente no ciclo do ouro, quando a Coroa portuguesa exigia pagamento de elevados percentuais sobre a produção dessa riqueza (o quinto do ouro), bem como sobre a extração das pedras preciosas (Bordin, 2002). Vinte por cento das riquezas brasileiras iam para os cofres europeus. Portugal ainda cobrava os direitos alfandegários sobre todo o comércio exterior do Brasil.

Pagar tributos e não usufruir os benefícios que eles devem proporcionar, bem como a inexistência de mecanismos legais para discutir esses impostos, revoltou os brasileiros. A Inconfidência Mineira (1788-92) caracterizou-se pela tentativa de evitar a "derrama", termo utilizado para designar a cobrança de impostos atrasados, efetuada de forma violenta, rígida e severa, por parte da Coroa portuguesa (Maxwell, 1978).

Quando o Brasil se tornou independente de Portugal, com a instituição e a cobrança de tributos pelo governo brasileiro, foram estabelecidos limites e fundamentos de direito tributário, os quais resultaram no atual Código Tributário Nacional (CTN). Hoje, o tributo cobrado no Brasil tem finalidade social, sendo dever do cidadão pagá-lo e, em contrapartida, dever do Estado aplicálo em benefício do bem-estar comum.

A história descrita explica a cultura brasileira de resistência em pagar imposto; há um imaginário instituído de que o governo não merece arrecadar porque aplica mal (Corrêa, 1996). Ainda, há consenso social de que é "inteligente" quem engana o fisco e/ou deixa de cumprir as obrigações tributárias. Tal situação se expressa na ausência de consciência cidadã, com conseqüente descuido e desinteresse pela coisa pública. O desvio das receitas públicas, que deveriam ser vertidas de forma espontânea ao Estado, aliado à falta de consciência cidadã, tem atravancado a evolução e a modernização do país em termos gerenciais.

\section{Dinâmica do sistema tributário nacional}

O sistema tributário nacional limita-se a definir as competências tributárias, enquanto conceitos e definições constam no CTN, que define tributo como "toda prestação pecuniária compulsória, em moeda ou cujo valor nela se possa exprimir, que não constitua sanção de ato ilícito, instituída em lei e cobrada mediante atividade administrativa plenamente vinculada" (art. $3^{\circ}$ ). Assim, considerase receita o "que o Estado arrecada mediante o emprego da sua soberania, nos termos fixados em lei, sem contraprestação diretamente equivalente, e cujo 
produto se destina ao custeio das finalidades que lhe são próprias" (Sousa, 1975:39).

Independente das questões conceituais, o tributo é a participação obrigatória do indivíduo, da empresa e da instituição para o financiamento dos gastos do ente tributante para a manutenção e a prestação de serviços públicos. Essa obrigação tributária é o exercício de poder jurídico "por força do qual uma pessoa (sujeito ativo) pode exigir de outra (sujeito passivo) uma prestação positiva ou negativa (objeto da obrigação) em virtude de uma circunstância reconhecida pelo direito como produzindo aquele efeito (causa da obrigação)" (Sousa, 1975:83).

Embora existam diversas fontes de receitas tributárias (Fabretti, 2000), o Estado busca mais recursos na sociedade. De outra parte, o contribuinte procura proteger-se através de ações no Judiciário, realizando planejamento tributário ou praticando a sonegação fiscal.

Desse embate dual na busca de recursos emergem dois fenômenos sociais: a evasão e a elisão fiscal. Segundo Huck (1997:3), evasão e elisão fiscal são fenômenos sociais que coexistem com a figura do imposto, não importando o grau de desenvolvimento econômico ou cultural do povo, pois o objetivo de sempre pagar menos impostos é uma constante na sociedade.

Para o mesmo autor, evasão e elisão têm em comum a característica de serem técnicas de não-submissão à norma tributária. Para fugir ao tributo o contribuinte escolhe caminhos alternativos desviantes do campo da tributação, fugindo ao alcance da norma tributária, ou, caso já estiver no campo da incidência, utiliza-se de meios ilícitos para impedir, reduzir ou retardar o recolhimento do imposto devido.

Corrêa (1996:28) considera que a elisão fiscal é "o retardamento, a redução ou a descaracterização do fato gerador que dá origem ao pagamento de um tributo, sem contudo violar a lei". Na visão de Huck (1997), é a faculdade do indivíduo em estruturar seu negócio jurídico de forma lícita, através dos meios disponíveis no direito privado, de modo a não constituir o fato gerador, abortando o nascimento da obrigação tributária. É o planejamento tributário! Ambos os autores reconhecem que a linha divisória entre elisão e evasão fiscal é, em alguns casos, muito tênue, visto o impacto semelhante que causam no sistema tributário do país.

O descumprimento da norma tributária configura o ilícito administrativo tributário passível de cominação de multa pelas autoridades competentes. Caso o ilícito seja relativo à obrigação principal, ou seja, deixar de pagar o tributo e tendo sido utilizada para tanto uma prática qualificada de sonegação, a penalidade pecuniária é agravada, incorrendo aquele que praticou tais atos em crime passível de processo penal. 
Os crimes contra a ordem tributária e outras matérias correlatas são disciplinados pela Lei $\mathrm{n}-8.137 / 90$. Sua importância está diretamente relacionada à extensão e ao volume atingido pela sonegação fiscal no país, acarretando prejuízos significativos para a administração pública, que se vê privada de recursos que poderiam ser aplicados nas atividades do Estado.

A referida lei define crime como sendo não apenas as condutas realizadas pelo contribuinte infrator, mas também pelos funcionários públicos. A lei também fixa as penalidades (penas privativas de liberdade ou pecuniárias) ou medidas de segurança. As condutas mais graves são alcançadas pelas regras do direito penal, e aquele que realiza conduta prevista como crime contra a ordem tributária está sujeito não apenas a sanções civis e administrativas, mas também a sanções de natureza penal.

As sanções civis visam obter a reparação do prejuízo causado ao Estado. As sanções administrativas se dão mediante a aplicação de multas administrativas e eventual restrição ao exercício das atividades e, contra o funcionário público (caso se trate de crime cometido por ele), através de sanções disciplinares - demissão do serviço público e incompatibilização com o exercício de outro cargo público por determinado período de tempo.

\section{A educação fiscal no Brasil}

No Brasil, a tributação e todos os seus elementos de conteúdo econômico e social ainda são tidos como desobrigados de qualquer entendimento pelo cidadão, caracterizando-se como atividade particular e interna do Estado. Tanto o governo quanto os canais de comunicação popular fornecem explicações mínimas sobre a tributação e as suas implicações na vida das empresas e das pessoas. Informações sobre as finanças públicas, principalmente os gastos do governo, não são divulgadas para o cidadão comum. A esse resta a condição de simples leitor do noticiário sobre elevação da carga tributária, criação de novos tributos, injustiças fiscais, aumento dos gastos públicos, déficit público, desvio de recursos, desequilíbrio das finanças públicas e seus efeitos sobre a inflação.

Com o objetivo de aumentar a arrecadação, inúmeras campanhas foram realizadas incentivando a emissão de notas fiscais nas relações comerciais e de serviços, a exemplo da campanha "Paguei Quero Nota" realizada no estado do Rio Grande do Sul em passado recente. Essas campanhas, em que pese ao objetivo preciso de aumento de arrecadação, tinham certo cunho educativo, com informações sobre a história e as finalidades dos tributos. No en- 
tanto não se prestavam a incutir na sociedade uma consciência mais clara sobre tributação e finanças públicas.

Programas planejados para se tornarem meio eficiente de educação sobre a questão fiscal foram lançados de forma esparsa e, via de regra, abandonados antes de atingirem seus objetivos. Em 1969 foi lançada a primeira ação educativa na área da administração fiscal da União, a "operação bandeirante". Os agentes do fisco tinham a missão de ensinar "a não pagar multas". A força dessa operação era o ensino sobre a função socioeconômica dos tributos e sua materialização através das obras de infra-estrutura (Pnef, 2002).

Em 1970, com a operação Brasil do Futuro, a educação tributária buscava chegar aos estabelecimentos de ensino. A publicação Dona Formiga, Mestre Tatu e o imposto de renda, de Cecília Lopes da Rocha Bastos, foi distribuída nas escolas do ensino fundamental. $\mathrm{O}$ objetivo era levar às crianças elementos básicos para a formação de uma consciência substitutiva do estado de guerra entre o fisco e a sociedade. Essa atividade atacava os vícios culturais, promovendo a aceitação popular de três idéias: indispensabilidade dos tributos nas aspirações de desenvolvimento; vantagens da cooperação; poupança ou a descoberta do futuro. Apesar de seus méritos, o trabalho foi suspenso em 1972. Argumentava-se que essa atividade pertencia ao sistema educacional e que a obtenção de resultados somente se faria sentir em um prazo muito distante.

Em 1977, a Secretaria da Receita Federal lançou o programa Contribuinte do Futuro mediante trabalho junto aos estabelecimentos de ensino e distribuição de livros e cartilhas a alunos e professores. O objetivo era a ampliação da consciência sobre a função social do tributo para melhorar a disposição de contribuir para as finanças do Estado, ficando sempre caracterizada a meta de aumentar a arrecadação tributária. Esse trabalho, caracterizado com rótulo de "campanha", não alcançou a condição de atividade permanente por falta de compreensão da sua especialidade e pela dependência dessa ou daquela administração.

Nos anos 1980 e o início dos anos 1990, alguns estados brasileiros implementaram trabalhos de educação tributária nos estabelecimentos de ensino. Muitos deles também foram interrompidos, demonstrando que os administradores públicos, sucessivamente, minimizam os efeitos positivos potenciais da educação fiscal (Pnef, 2002).

Novas expectativas começaram a se criar para a questão da educação fiscal a partir dos seminários promovidos pelo Conselho Nacional de Política Fazendária, em 1995, sobre federalismo fiscal e, em 1996, sobre administração tributária, nos quais diversos expositores chamaram a atenção para a questão da educação tributária. No encerramento do último seminário, um 
dos itens de destaque foi: "a introdução, nas escolas, do ensino do programa de consciência tributária é fundamental para despertar nos jovens a prática da cidadania, o respeito ao bem comum e a certeza de que o bem-estar social somente se consegue com a conscientização de todos" (Pnef, 2002).

Em setembro de 1996, celebrou-se o Convênio de Cooperação Técnica entre a União, os estados e o Distrito Federal. No anexo ao texto do acordo, entre as inúmeras atividades cooperativas, constaram a elaboração e a implementação de um programa nacional permanente de conscientização tributária para ser desenvolvido nas unidades da Federação.

Na mesma época foi criado o Programa Nacional de Apoio à Administração Fiscal para os Estados Brasileiros com recursos financeiros oriundos de empréstimos junto ao Banco Interamericano de Desenvolvimento (BID). O regulamento operativo objetivava "melhorar a eficiência administrativa, a realização e a transparência na gestão dos recursos públicos estaduais" e, então, foram previstos projetos de modernização fiscal (Pnef, 2002).

Em 1997, o Conselho Nacional de Política Fazendária (Confaz) aprovou a criação do grupo de trabalho Educação Tributária, constituído por representantes do Ministério da Fazenda, das secretarias de Fazenda, Finanças ou Tributação dos Estados e do Distrito Federal. Oficializado por portaria ministerial, o grupo de trabalho objetivava "promover e coordenar as ações necessárias à elaboração e à implementação de um programa nacional permanente de educação tributária" e "acompanhar as atividades do grupo Educação Tributária nos Estados" (Pnef, 2002).

Em março de 1999 passaram a integrar o grupo os representantes da Secretaria do Tesouro Nacional e do Ministério da Educação. Ainda em julho do mesmo ano, tendo em vista a abrangência do programa não se restringir apenas aos tributos, abordando também as questões da alocação dos recursos públicos e da sua gestão, o Confaz aprovou a alteração de sua denominação para Programa Nacional de Educação Fiscal (Pnef).

O Pnef busca promover o entendimento coletivo da necessidade e da função social do tributo, assim como dos aspectos relativos à administração dos recursos públicos. Com o envolvimento do cidadão no acompanhamento dos gastos públicos, estabelece-se controle social sobre o desempenho dos administradores públicos e asseguram-se melhores resultados sociais. $\mathrm{O}$ aumento da cumplicidade do cidadão em relação às finanças públicas torna mais harmônica sua relação com o Estado. Esse é o estágio de convivência social desejável e esperado.

Nesse contexto e analisando a necessidade de orientação do indivíduo quanto aos mecanismos de controle existentes no serviço público, a educação fiscal serve também para capacitar o cidadão a reclamar no momento oportu- 
no junto às autoridades e aos órgãos competentes, fortalecendo-o para o exercício de seus direitos sociais, estimulando-o a desenvolver o espírito comunitário, conscientizando-o da responsabilidade individual para com a coletividade e buscando valorizar os tributos pagos.

O Pnef é incipiente e ainda vive-se no Brasil um estado de profundo desconhecimento das bases da sociedade em relação às coisas mais elementares, agravado, no caso do tributo, pela sua natureza impositiva. Ainda confunde-se Estado com governo; contribuinte de direito com contribuinte de fato; governo com funcionário público e não se tem claro que o criador do Estado e, portanto, dos seus tributos, é o próprio povo. Se o sistema tributário nacional é "injusto", existem caminhos adequados para mudá-lo, não servindo tal fato de justificativa para a sonegação (Pnef, 2002). Esse quadro evidencia a importância de programas, tanto de iniciativa privada quanto pública, que tenham por fim desenvolver a consciência fiscal no cidadão brasileiro.

Com programas de educação fiscal se desperta o cidadão para a importância do pagamento espontâneo dos tributos e, por outro lado, dá-se importância a sua participação em câmaras municipais, assembléias legislativas, reuniões comunitárias, associações de bairro, associações de classe e sindicatos a fim de eleger as prioridades no planejamento e nos orçamentos da administração pública, cobrar a execução e acompanhar efetivamente a aplicação dos recursos públicos.

\section{Procedimentos metodológicos}

O estudo seguiu o método de investigação quali-quantitativo, uma vez que busca obter dois tipos de informação: a descritiva, em relação ao recolhimento dos tributos, e a comportamental, em relação ao "ato espontâneo" de fazêlo. Para tanto se utilizou a técnica de coleta dos dados primários "pesquisa de campo" (Rea e Parker, 2000).

Os sujeitos envolvidos na pesquisa são empresários e os dados foram coletados no primeiro semestre de 2003. O instrumento de coleta foi o questionário semi-estruturado que buscou elementos característicos dos sujeitos pesquisados e o seu grau de comprometimento (social e ético) relacionados ao recolhimento espontâneo de tributos. Em etapa anterior foi preciso realizar minuciosa pesquisa em fontes bibliográficas do direito para a obtenção de dados secundários que serviram para instrumentalizar teoricamente o autor na elaboração do instrumento e na discussão dos dados encontrados na realidade. 
Foram priorizadas as respostas subjetivas dos sujeitos investigados e essas foram correlacionados aos perfis profissional e social dos mesmos, medidos através de escalas sociais. Os dados coletados foram submetidos à análise estatística descritiva simples (software SPSS). Classificou-se a natureza da atividade e, num segundo momento, discutiram-se os resultados observados. $\mathrm{Na}$ etapa seguinte foram anotadas as freqüências de cada categoria e calculado o percentual representativo sobre o total observado. Os dados foram manipulados com base nos preceitos teóricos do conceito "educação fiscal".

$\mathrm{O}$ universo da pesquisa está representado pelas empresas cadastradas no Cadastro Geral de Contribuinte do Tesouro do Estado localizadas no município de Passo Fundo (RS), identificadas na situação cadastral ativa, com movimento até março de 2003, excluídas as empresas da categoria microempresa em razão de as mesmas serem isentas do recolhimento do imposto sobre circulação de mercadorias e serviços (ICMS). O Sistema de Cadastro da Receita Pública Estadual distingue o porte das empresas, além de indicar se o contribuinte está ativo ou inativo (baixado). Dessa relação foi calculado o tamanho da amostra, considerando-se a proposta metodológica de Gil (1999) para populações finitas, nível de confiança igual a 95\% e margem de erro de $8 \%$. O cálculo resultou numa amostra de 96 empresas selecionadas aleatoriamente na relação disponível.

Como limitação do estudo apresentam-se o espaço geográfico (um município) e as variáveis regionais (formação cultural do povo), que impedem a generalização dos dados para outras regiões geográficas do país, mas permitem replicação do mesmo modelo de análise.

\section{Resultados da pesquisa}

A partir do agrupamento dos dados coletados, primeiramente define-se o perfil das empresas a que pertencem os sujeitos pesquisados. Na seqüência apresenta-se a compreensão conceitual dos sujeitos quanto à cobrança e ao pagamento dos tributos e a percepção dos entrevistados quanto à aplicação dos recursos arrecadados. Os dados são resultado de análise univariada, de freqüência simples e de média, correlações e análise interpretativa das questões abertas.

\section{Caracterização da amostra e perfil dos respondentes}

O segmento de atuação das empresas da amostra concentra-se no comércio, na reparação de veículos, objetos pessoais e domésticos $(62,77 \%)$, na indústria de transformação $(10,64 \%)$ e nos serviços de alojamento e alimentação 
(9,57\%). O nível de faturamento anual das empresas indica que a pesquisa retrata a opinião dos dirigentes de empresas de micro e pequeno portes, visto que a maior freqüência $(59,55 \%)$ ficou em empresas com faturamento de até $\mathrm{R} \$ 244 \mathrm{mil} / \mathrm{ano}$. As firmas com faturamento entre $\mathrm{R} \$ 244 \mathrm{mil}$ e $\mathrm{R} \$ 1,2 \mathrm{mi}$ lhão representam $30,34 \%$ da amostra, enquanto $10,11 \%$ faturam mais de $R \$$ 1,2 milhão/ano.

O número de pessoas ocupadas por empresa é variado, com a maior freqüência em empresas que possuem entre zero e cinco empregados $(52,13 \%)$. Aquelas que possuem entre seis e 10 representam 19,15\% da amostra. A média de idade das empresas é de 14,9 anos. A firma com mais tempo de existência opera há 82 anos, enquanto a que opera há menos tempo foi fundada há um ano.

Os respondentes são proprietários das empresas (54,22\%), gerentes $(21,69 \%)$ e administradores (12,05\%), totalizando $87,96 \%$ da amostra. Trinta e sete por cento desses estão na empresa há, no máximo, cinco anos e $16,67 \%$ atuam, em média, há 13 anos. A grande maioria possui entre 26 e 55 anos de idade e a maior concentração está na faixa etária entre 36 e 45 anos $(36,91 \%)$ e entre 46 e 55 anos (25\%); são predominantemente do sexo masculino $(71,87 \%)$ e $74,19 \%$ são casados. Fazendo-se a correlação do estado civil com o sexo dos respondentes, tem-se que, dos 69 casados, a maioria é composta por homens. A relevância desse dado está na possível influência do sentimento de responsabilidade que indivíduos casados sentem em relação ao meio social.

Igualmente importante é a escolaridade dos respondentes: 44,79\% são graduados; $11,46 \%$ estão cursando o nível superior (graduação incompleta); 4,17\% são pós-graduados e 1,04\% possuem mestrado. Considerando que $32,29 \%$ dos entrevistados possuem ensino médio e $6,25 \%$ cursaram o ensino fundamental, constata-se que à frente das empresas estão pessoas com formação educacional em nível elevado.

Entre os cursos de graduação predominam os de administração $(14,8 \%)$, de ciências contábeis $(9,3 \%)$ e de economia $(7,4 \%)$, ou seja, cursos que preparam profissionais na área das ciências sociais aplicadas. Outro fator relevante apontado na pesquisa refere-se aos $41,9 \%$ dos respondentes graduados com registro na categoria profissional. Entre os graduados em administração, no entanto, constatou-se apenas um profissional registrado. Dado preocupante para a categoria!

Em síntese, o padrão predominante do perfil dos respondentes é de sócios-proprietários, gerentes e administradores de empresas de micro e pequeno portes, que atuam no ramo de comércio, reparação de veículos e objetos pessoais. Fato relevante é que os mesmos são graduados ou estão matriculados em cursos de ensino superior, o que qualifica e valoriza os resultados da pesquisa. 


\section{Percepção quanto à cobrança e ao pagamento dos tributos}

Com o intuito de avaliar o grau de comprometimento da empresa em relação à questão tributária, um item do questionário solicitava que fosse indicado qual a pessoa responsável pelo cálculo e pela apuração dos tributos a serem recolhidos mensalmente. A maior parte das empresas delega a responsabilidade ao escritório de contabilidade que lhe presta serviços $(58,33 \%)$ ou ao contador $(37,50 \%)$ que trabalha na própria empresa. Depreende-se desse resultado que a questão tributária não faz parte das preocupações principais dos gestores.

Para avaliar se o empresário tem noção de quanto os tributos recolhidos significam, em termos percentuais, do faturamento da sua empresa foi apresentada uma questão desestruturada que solicitava ao respondente um posicionamento em termos quantitativos. As respostas apontam uma escala que varia de $3 \%$ a $88 \%$, com $21,88 \%$ concentrando-se na faixa de $20,1 \%$ a $30 \%$ e $17,71 \%$ na faixa de $3 \%$ a $10 \%$.

A maior parte dos empresários não tem noção exata de quanto os valores recolhidos a título de tributo representam no faturamento da empresa, eis que apenas $32,29 \%$ afirmaram que tal percentual varia entre $3 \%$ e $20 \%$. Ora, como $55,21 \%$ dos entrevistados trabalham em micro e pequenas empresas, que têm tributação reduzida em níveis federal e estadual, pode-se afirmar que essas, enquanto enquadradas nesse regime tributário, jamais ultrapassarão $15 \%$ na relação tributo recolhido versus faturamento.

A falta de clareza da relação entre os tributos recolhidos e o faturamento da empresa é confirmada pelo fato de $30,2 \%$ dos entrevistados não terem respondido a essa questão e por 6,23\% terem afirmado que essa relação seria maior que $40 \%$, um dado que não condiz com a realidade.

Para saber como o empresário considera o percentual de tributos recolhidos sobre o valor do faturamento mensal da empresa, foram apresentadas três opções para avaliação: percentual baixo, médio ou alto. Os resultados estão dispostos na figura. Para 83,33\%, o percentual de tributos recolhidos sobre o faturamento é considerado elevado pelos empresários. Comparando-se os dados, depreende-se que, embora $30,2 \%$ dos entrevistados não tenham respondido quanto representa, em termos percentuais, o recolhimento dos tributos sobre o valor do faturamento mensal da empresa, e que os demais dados coletados demonstram uma opinião variada - carga tributária entre $3 \%$ e $88 \%$ do faturamento - , a maioria considera a carga tributária com percentual elevado e incompatível com as atividades. 

Percepção dos respondentes na relação tributos
recolhidos/faturamento mensal

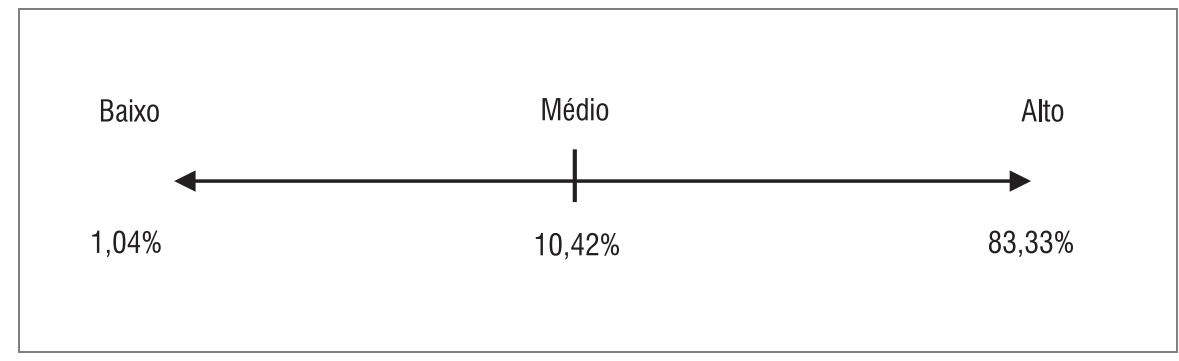

Fonte: Dados da pesquisa (2003).

O tributo que mais onera a atividade empresarial, na visão dos entrevistados, é o ICMS (50\%), seguido pelo Plano de Integração Social (PIS) e pela Contribuição para o Financiamento da Seguridade Social (Cofins) (14,3\%), Simples $(10,2 \%)$, encargos sociais $(9,18 \%)$ e imposto de renda (IR) $(6,12 \%)$. A maior parte dos empresários sabe realmente qual tributo mais onera a atividade. O ICMS, em função da alíquota-base de 17\%, impõe às empresas contribuintes alto índice na relação faturamento/imposto recolhido. Tal índice pode chegar a $6,4 \%$ do faturamento nos casos em que o empresário opere com uma margem de valor adicionado de $60 \%$.

Para avaliar a postura dos empresários em relação ao recolhimento dos tributos, foram-lhes dadas duas alternativas de resposta. Na visão de $76 \%$ dos entrevistados, eles utilizariam o recurso para saldar o débito de imposto, pois preferem não ficar em débito com os cofres públicos. O que motiva $84,21 \%$ deles a fazer isso é a obrigação, por receio de serem multados pela fiscalização; não há consciência cidadã no ato do recolhimento espontâneo. Apenas $11,58 \%$ efetuam o recolhimento por considerarem isso fundamental para a existência e a manutenção do Estado, enquanto outros 4,21\% efetuam o recolhimento por ambos os motivos indicados.

Para avaliar a postura dos empresários em relação ao pagamento dos tributos devidos e à elevada carga tributária, numa questão afirmou-se que, "em função da alta carga tributária brasileira, parte dos empresários deixa de declarar percentual do faturamento para diminuir o valor dos tributos a serem pagos". A partir daí questionou-se o respondente em relação a tal postura, solicitando-lhe que indicasse sua posição através das opções apresentadas ou opinasse de acordo com sua percepção.

Dos dados abstraiu-se que $42,71 \%$ não concordam em deixar de declarar percentual do faturamento, embora entendam que essa, às vezes, é a úni- 
ca forma de a empresa sobreviver. Outros indicaram como incorreta tal postura em função de gerar concorrência desleal $(21,87 \%)$ ou por entenderem que o cumprimento das obrigações tributárias é uma obrigação e independe da carga tributária $(22,92 \%)$.

Mesmo se o governo melhorasse a divulgação da aplicação dos recursos arrecadados, apenas $57,61 \%$ teriam motivação para fazê-lo. Para $21,74 \%$ não teria qualquer efeito motivacional, e para $20,65 \%$ é indiferente. Pelas justificativas da maioria desses $(64,15 \%)$, o que os motiva a assumir tal postura é saber onde os recursos são aplicados, e se o são de forma correta (consciência da finalidade "arrecadatória"). Entre os $21,74 \%$ daqueles que responderam que a divulgação não influenciaria na motivação para recolher espontaneamente os tributos, as justificativas são de que "o governo precisa 'fazer', não divulgar" (15\%); "não adianta divulgar, o problema está na aplicação, nos desperdícios, nos excessos, nos desvios" (15\%); "não existe recolhimento espontâneo" (15\%). Aos indiferentes $(20,65 \%)$, a principal justificativa foi que "o recolhimento é efetuado independente de divulgação" $(26,32 \%)$ e, para outros, "a carga tributária elevada impede o recolhimento espontâneo dos tributos”.

Porém a maioria dos empresários não tem noção do que significa "recolhimento espontâneo"; 26,04\% deixaram de responder à questão e muitas respostas não se referiam à pergunta. Inclusive $19,78 \%$ dos respondentes consideram pagamento espontâneo aquele que seria efetuado a título de doação, independente de norma que o exija. Outras respostas ("pagar a quantia que considerar justa" e "contribuição que tem que existir para o crescimento do estado") também confirmam haver equívoco quanto ao significado da expressão. Apenas 11,45\% dos entrevistados demonstraram entender que pagamento espontâneo tem relação com pagar os tributos conforme previsto em lei. Outros 9,38\%, embora fazendo referência ao pagamento de tributos, deram ênfase ao prazo previsto para o pagamento, o que está parcialmente correto, eis que o prazo é apenas uma das regras a serem observadas, sendo o pagamento integral a mais importante.

Por fim, os empresários foram questionados para que se manifestassem espontaneamente sobre o que mudariam no atual sistema de recolhimento de impostos, caso tivessem o poder de fazê-lo. Observou-se que $34,38 \%$ dos entrevistados instituiriam o imposto único, enquanto que para $20,83 \%$ a simples redução das alíquotas dos impostos seria o suficiente para melhorar o atual sistema.

Pelos dados expostos, de modo geral pode-se dizer que a grande maioria dos empresários não dedica à questão tributária a devida atenção. Como atuam em empresas enquadradas como de micro e pequeno portes, com tributação reduzida tanto na área federal quanto estadual, possivelmente o juízo 
que fazem a respeito dos tributos e da carga tributária tenha origem no noticiário econômico, que diariamente afirma ser muito elevada a carga tributária brasileira. De outra parte, declaram não concordar com a prática da sonegação fiscal, admitindo, no entanto, praticá-la. Quando recolhem os tributos, fazem-no mais por receio de serem autuados pela fiscalização do que por uma consciência de cidadania.

\section{Percepção quanto à aplicação dos recursos arrecadados}

Questionaram-se os entrevistados sobre o grau que os governos (federal, estadual e municipal) procuram difundir ou esclarecer onde e como os recursos arrecadados são aplicados. Numa escala de um a cinco foi medido o grau de percepção. A maioria dos entrevistados $(48,39 \%)$ afirma que o governo não esclarece onde e como os recursos arrecadados são aplicados; $30,11 \%$ consideram baixo o nível de esclarecimento disponibilizado; e outros $16,13 \%$ consideram o nível insuficiente. Apenas 5,38\% consideram haver um nível satisfatório de esclarecimento por parte do governo.

Quanto à percepção dos respondentes em relação à importância da função do governo de prestar serviços de saúde, educação e segurança, 97,85\% afirmaram ser essa uma função prioritária do governo. As justificativas apontadas foram variadas: $25 \%$ consideram essa atuação função principal do governo para promover o bem-estar dos cidadãos; para 3,13\%, tal atuação é importante, não por se tratar da principal função do governo, mas porque são nessas áreas que residem as necessidades básicas da população; 5,21\% consideram tais serviços importantes, porém precários, deixando transparecer a insatisfação quanto à atuação do governo nessas áreas. Outros 4,17\% confirmaram a importância dessa função do governo, enfatizando a questão da educação como prioritária.

Quanto ao grau de satisfação pelos serviços sociais prestados pelo governo, a maioria dos respondentes o considera insuficiente; o governo arrecada muito e oferece pouco $(78,13 \%)$. Apenas $2,08 \%$ acham que o nível de serviços prestados é suficiente e atendem as necessidades básicas da população. O mesmo percentual diz que os serviços são insuficientes, mas, para aumentar sua qualidade e quantidade, o governo deveria dispor de mais recursos. Os 16,67\% restantes, embora com opiniões bem variadas, enquadram-se numa mesma linha de pensamento: os serviços são insuficientes não porque o governo arrecada pouco, mas porque os recursos arrecadados são mal administrados.

Pretendendo-se verificar se o empresariado tem noção aproximada de para onde é vertido o maior volume dos recursos arrecadados pela União, for- 
mulou-se questão desestruturada na qual os entrevistados puderam citar espontaneamente as suas respostas, as quais, novamente, apresentaram-se bem variadas. Entre essas, as áreas da saúde e da educação foram mencionadas como as que mais recebem recursos $(18,27 \%)$, seguidas pela folha de pagamento do funcionalismo público $(13,46 \%)$. Importante parcela dos empresários $(10,58 \%)$ considera que o maior volume dos recursos é desviado para enriquecimento de particulares, alimentando a estrutura de corrupção instalada no país. Para $6,73 \%$ dos respondentes o setor da previdência social é o que recebe o maior volume de recursos. Do total, 19,23\% dos entrevistados não souberam responder à questão.

Com o intuito de verificar o que é entendido pela expressão "educação fiscal" e para medir o nível de responsabilidade em relação à questão tributária, foram solicitadas respostas espontâneas dos empresários. Observou-se que eles não têm compreensão conceitual, haja vista a diversidade de respostas fora da temática e o elevado índice de não-respondentes $(26,04 \%)$. O conceito que apareceu com maior freqüência está associado à idéia de "informações sobre o recolhimento, a aplicação e o retorno dos tributos à população" $(15,63 \%)$ como um processo de doutrinamento $(11,46 \%)$ ou conscientização $(5,21 \%)$ do ato de pagar os impostos, bem como a campanhas de divulgação da obrigação de efetuar o pagamento $(7,29 \%)$. Não foram inseridas quaisquer referências relacionadas à aplicação dos recursos arrecadados e ao direito dos contribuintes de fiscalizarem o destino desses recursos.

Esse arcabouço exploratório permite efetuar análises a respeito das questões tributária e fiscal na concepção dos sujeitos entrevistados, enfatizando o conhecimento da questão tributária, o pagamento e a aplicação dos tributos, bem como a sua aplicação.

\section{Análise dos resultados}

A partir dos dados coletados, estratificados de acordo com os procedimentos metodológicos e correlações que pudessem exprimir as convicções, os anseios, as posturas e as críticas dos entrevistados em relação às questões tributária e fiscal, a presente seção sintetiza os resultados e apresenta propostas para o debate de programas de educação fiscal.

Entre as primeiras constatações está a aparente falta de comprometimento do empresário a respeito do montante e dos tipos de tributos que paga. Apenas um dos entrevistados calcula seus impostos e os demais têm visão difusa de quanto os tributos representam do faturamento. Dois terços afirmaram que tal índice seria superior a $20 \%$; mas, pela condição de contribuinte, o máximo é $15 \%$. 
Embora a responsabilidade da apuração e do cálculo dos tributos a pagar seja delegada a "outros profissionais" da empresa $(40,63 \%)$ ou terceirizada $(58,33 \%)$, a falta de noção aproximada da carga tributária sofrida pela empresa consolida o fato de que os tributos não estão entre as principais preocupações dos entrevistados. Sem ter ciência da representatividade dos tributos recolhidos versus faturamento, 83,33\% dos empresários afirmam que o índice é elevado. Esse posicionamento pode ser atribuído à carga tributária geral do país ou à rejeição aos tributos, comum ao cidadão brasileiro.

Essa constatação se confronta com o discurso rotineiro dos empresários nos meios de comunicação, que reclamam ao governo a redução da carga tributária. Ora, se eles não têm noção exata de qual é a carga tributária sofrida pela empresa, como podem afirmar que ela é elevada? Os dados indicam que a opinião pode estar influenciada pela mídia, que promove discussões em torno da carga tributária brasileira. Essa, em 2002, conforme estudos da Coordenação Geral de Política Tributária da Receita Federal, foi de $35,86 \%$ do PIB,${ }^{1}$ considerada elevada pelo empresariado e pelos economistas.

Solicitado aos empresários para que se posicionassem entre pagar débito de impostos ou realizar investimentos, $76,6 \%$ responderam que pagariam os tributos. No entanto, $84,21 \%$ deles só o fazem por receio de serem multados pela fiscalização. Apenas um pequeno número de empresários efetua o pagamento como ato de cidadania. De forma geral, não possuem juízo formado a respeito dos mecanismos de construção, organização e sustentação da coletividade; não visualizam nos tributos elemento fundamental para a existência da sociedade organizada.

As respostas às questões que envolvem o posicionamento do empresário ante a sonegação fiscal e o índice da carga tributária geram contradições e ambigüidades. Noventa e um por cento dos entrevistados não apóiam ações de sonegação, mas admitem fazê-lo; 23,91\% rejeitam a sonegação por entenderem que é obrigação de todos cumprir as exigências tributárias, mesmo que signifique ônus elevado ao contribuinte; $67,4 \%$ admitem ou aceitam quem pratica a sonegação; $22 \%$ sustentam que essa prática gera concorrência desleal entre as empresas, alterando a dinâmica do mercado. Tem-se, assim, que a

\footnotetext{
${ }^{1} \mathrm{O}$ conceito de carga tributária utilizado é amplo e inclui contribuições sociais, de intervenção no domínio econômico e de interesse de categorias profissionais e econômicas, além de impostos, taxas e contribuições de melhorias de acordo com o art. 145 (CF/88) e das contribuições para o Fundo de Garantia do Tempo de Serviço (FGTS). A estimativa considera os tributos e contribuições relativos às três esferas de governo, e o resultado constitui indicador do esforço social para financiamento de atividades do Estado.
} 
maior parte dos empresários não considera o cumprimento da legislação tributária parte dos direitos e deveres inerentes às pessoas que convivem em sociedade.

Em relação ao recolhimento espontâneo dos tributos, grande parte dos empresários não tem convicção do que seja essa prática. Mais de um terço dos entrevistados associa pagamento espontâneo a "doação espontânea" (19,78\%), pagamento de "quantia justa" $(5,21 \%)$ ou simplesmente nega existir pagamento espontâneo (7,29\%). Apenas 11,45\% deixaram transparecer que recolher os tributos de forma espontânea está associado à idéia de cumprir a legislação tributária integralmente, observando o montante a ser pago e os prazos previstos, independentemente de notificação dos órgãos fiscalizadores.

Embora confusos, 57,61\% dos empresários afirmam que a divulgação das formas de aplicação dos recursos arrecadados seria fator motivador para o recolhimento espontâneo dos tributos; $42,39 \%$ não consideram que essa divulgação tenha influência sobre a arrecadação, pelas elevadas alíquotas praticadas e pela percepção do pouco que é feito com o que o governo arrecada. Então, a redução da carga tributária e a simplificação das obrigações seriam fatores motivadores de recolhimento espontâneo.

Embora a resposta mais freqüente tenha sido no sentido da instituição de imposto único $(34,38 \%)$, que traduz a necessidade de simplificação das obrigações tributárias, o objetivo maior dessa proposição está na redução da carga tributária por acreditarem que esse tipo de imposto reduz a alíquota atual. $\mathrm{O}$ cruzamento dos dados permite afirmar que o grande interesse dos empresários está na redução da carga tributária total.

O sentimento de que a carga tributária é elevada está associado à não-divulgação, pelos governos, da aplicação dos recursos arrecadados; 94,63\% dos empresários afirmam que o governo não divulga adequadamente onde aplica as receitas tributárias. Não sabendo o destino que é dado aos valores recolhidos, qualquer quantia parece ser elevada para quem paga!

Os empresários se dizem "desinformados" sobre a questão tributária, fato comprovado quando lhes foi solicitado indicar a área pública que recebe o maior volume de recursos. Diferentes áreas (saúde, educação, segurança etc.) foram citadas, mas a literatura aponta o pagamento do funcionalismo público consumindo mais de $70 \%$ das receitas públicas. Em segundo lugar estão os gastos com o refinanciamento da dívida pública, que representou em torno de $49,75 \%$ do orçamento federal em 2003 (Brasil, Orçamento Geral da União, 2003b). Alguns responderam que o maior volume de recursos perde-se em meio à estrutura de corrupção instalada no país, deixando transparecer revolta e indignação com os insistentes e vultosos casos de desvio de verbas noticiados cotidianamente.

Quanto às funções do governo, 97,85\% dos empresários o consideram prestador de serviços de saúde, educação e segurança. Pelos preceitos consti- 
tucionais, no entanto, a função primordial do Estado é organizar e regular a vida em sociedade, gerando condições necessárias para o bem-estar social. Em relação a esses, o sentimento geral é de insatisfação; 78,95\% dos entrevistados os julgam insuficientes e alegam que o governo arrecada muito e oferece pouco. Essa posição tem relação estreita com a opinião generalizada de que a carga tributária é elevada, pois quem assim a considera possivelmente pensa que está pagando muito pelo que lhe é oferecido como retorno. Dois por cento julgam que os serviços são insuficientes, mas para que haja melhoria o governo deveria dispor de mais recursos. Poucos compreendem que, embora a carga tributária seja elevada, o montante arrecadado não é suficiente para atender as demandas básicas da coletividade brasileira.

Os resultados também apontam desconhecimento pela expressão "educação fiscal". A grande maioria a relaciona com "ensinar a pagar corretamente os tributos". Se considerados as respostas não inseridas no contexto e o alto índice de questões não respondidas, pode-se afirmar que a maior parte não tem entendimento firmado sobre o tema. Embora a expressão tenha sido relacionada ao recebimento de informações de como os impostos são recolhidos e aplicados e ao retorno que dão à população, ninguém referenciou os direitos dos contribuintes de acompanhar e influir na aplicação dos recursos.

A soma dos resultados obtidos evidencia o baixo grau de entendimento dos entrevistados a respeito da questão tributária, especialmente quanto ao aspecto de que essa faz parte dos direitos e deveres dos cidadãos. Da mesma forma percebeu-se a falta de clareza da função dos tributos como garantidores da existência do Estado e dos governos, responsáveis pela organização e promoção da vida em sociedade. Apesar de ter sido muito enfatizado pelos empresários o aspecto da elevada carga tributária e da insuficiência dos serviços prestados pelo governo, ficou latente também a falta de comprometimento dos mesmos em relação às obrigações tributárias, como se aquelas justificassem esta.

Pelo todo exposto, fica transparente a necessidade de uma forte atuação dos governos e da sociedade organizada no sentido de melhorar a relação entre o contribuinte/cidadão e o Estado. Na seção seguinte pretende-se apontar algumas ações ou possibilidades para fazer com que os cidadãos entendam a necessidade de acompanhar o destino das receitas arrecadadas e contribuam responsavelmente com a parte que cabe a cada um, a fim de que o Estado obtenha recursos financeiros suficientes para assegurar a aplicação das leis, manter as instituições que permitem o exercício dos direitos de cidadania e promover o bem social. 


\section{Considerações finais}

Numa situação ideal, os cidadãos deveriam conhecer a estrutura do Estado, o seu modelo de gestão e a política tributária, bem como acompanhar a estrutura "arrecadatória" e o destino que os administradores públicos dão aos recursos arrecadados. Consciente desses aspectos, o cidadão contribuinte adota comportamento cidadão diante da questão tributária, contribuindo espontaneamente com a parte que lhe cabe. A realidade brasileira demonstra que governo e sociedade estão longe de atingir tais padrões.

Os resultados da pesquisa demonstram falta de sintonia entre o que o cidadão espera e está disposto a contribuir e o que o governo oferece e exige em tributos e que pode ser suprido por programas de educação fiscal. Existe espaço para ações de conscientização social da função do Estado, da função socioeconômica do tributo e da necessidade de exercer o controle social dos gastos públicos. Uma ação primordial está na inclusão do tema educação fiscal na estrutura do ensino universitário com vistas a formar profissionais aptos a avaliar a atuação dos gestores públicos quanto à propriedade e à adequação das aplicações dos recursos públicos. Diferentemente a pesquisa revelou que empresários, mesmo graduados, não mostraram ter clareza sobre a função do Estado e dos tributos.

Este artigo, ao evidenciar empiricamente a falta de comprometimento dos empresários com o pagamento dos tributos, oferece subsídios para ações sociais que propõem mudança cultural do empresariado. É preciso visualizar nos tributos um instrumento de desenvolvimento econômico e social. Nesse sentido, propõem-se eventos promovidos pelo Estado e por entidades da classe empresarial e universidades para demonstrar o papel estratégico do Estado no fomento ao desenvolvimento econômico, bem como para reduzir desigualdades sociais. Isso pode ser possível mediante a arrecadação das receitas tributárias e o gerenciamento comprometido e responsável dos recursos arrecadados por parte do Estado.

Além das ações anteriormente propostas, entende-se fundamental a transparência da gestão pública. Os governos, através dos meios de comunicação, precisam expor, em linguagem de fácil compreensão, o que fazem com os recursos arrecadados. O Estado e a administração pública precisam difundir suas funções e o seu papel na sociedade, divulgando os serviços públicos disponíveis e a forma de oferecimento dos mesmos. Essas ações, além de responderem aos anseios dos cidadãos, valorizam a administração.

Educação de qualidade é um dos maiores bens que se podem disponibilizar à sociedade. Entretanto, necessariamente, deve abranger a educação fiscal, visto que traz em si os elementos fundamentais para a relação responsável e 
comprometida entre Estado e cidadão. A universidade tem um papel que vai além da simples formação de profissionais para o mercado. É claro que ela prepara o jovem para exercer uma profissão e fazer jus aos seus rendimentos. Mas, além disso, tem o papel de formar cidadãos conscientes, questionadores, renovadores e, até mesmo, revolucionários da sociedade. Neste sentido propõe-se às instituições universitárias a inserção do tema educação fiscal nos currículos de todos os cursos. Ao promover o aprimoramento da relação Estado-cidadão, a consciência sobre a função social do tributo e ao incentivar o acompanhamento dos gastos públicos, os novos graduados ajudarão a disseminar entre o empresariado e a população em geral os elementos básicos da educação fiscal.

\section{Referências bibliográficas}

BEBIANO, H. Orçamento público. Apostila do curso ministrado no Tribunal Superior do Trabalho. Brasília: Instituto de Estudos Empresariais, 2001.

BORDIN, L. C. V. A origem dos tributos. Estudos Econômico-Fiscais. Governo do Estado do Rio Grande do Sul, Secretaria da Fazenda, Departamento da Receita Pública Estadual, Divisão de Estudos Econômico-Tributários, ano 8, n. 9, nov. 2002.

BRASIL. Lei Federal nํㅡ 4.320, de 17 de março de 1964. Diário Oficial [da] República Federativa do Brasil, Poder Executivo, Brasília, DF, 23 mar. 1964.

Lei no 8.137, de 27 de dezembro de 1990. Diário Oficial [da] República Federativa do Brasil, Poder Executivo, Brasília, DF, 28 dez. 1990.

—. Código Tributário Nacional. Lei 5.172/66. 25. ed. São Paulo: Saraiva, 1996.

Lei Complementar nํㅜ 101, de 4 de maio de 2000. Diário Oficial [da] República Federativa do Brasil, Poder Executivo, Brasília, DF, 5 maio 2000a.

Lei $\mathrm{n}^{\mathrm{o}}$ 10.028, de 19 de outubro de 2000. Diário Oficial [da] República Federativa do Brasil, Poder Executivo, Brasília, DF, 20 out. 2000b.

—. Constituição da República Federativa do Brasil de 1988. 31. ed. São Paulo: Saraiva, 2003a.

Orçamento Geral da União 2003. Disponível em: <www.planejamento.gov.br> Acesso em: 2 jul. 2003b.

RECEITA FEDERAL. Educação fiscal. Disponível em: <www.receita.fazenda.gov.br>. Acesso em: 26 ago. 2002.

Rap Rio de Janeiro 40(5):841-64, Set./Out. 2006 
RECEITA FEDERAL. Coordenação-Geral de Política Tributária. Estudos Tributários 11: Carga Tributária no Brasil — 2002. Brasília, abril 2003.

CORRÊA, A. Dos crimes contra a ordem tributária: comentários à Lei nํㅜ 8.137/90. 2. ed. São Paulo: Saraiva, 1996.

DALLARI, D. A. Elementos de teoria geral do Estado. 20. ed. São Paulo: Saraiva, 1998.

FABRETTI, L. C. Contabilidade tributária. 6. ed. São Paulo: Atlas, 2000.

GASPARINI, D. Direito administrativo. 4. ed. revista e ampliada. São Paulo: Saraiva, 1995.

GIL, A. C. Métodos e técnicas de pesquisa social. São Paulo: Atlas, 1999.

GUSMÃO, P. D. Introdução ao estudo do direito. 12. ed. Rio de Janeiro: Forense, 1986.

HUCK, H. M. Evasão e elisão: rotas nacionais e internacionais do planejamento tributário. São Paulo: Saraiva, 1997.

MAXWELL, K. R. A devassa da Devassa: a Inconfidência Mineira, Brasil-Portugal - 17501808. 2. ed. Rio de Janeiro: Paz e Terra, 1978.

MEIRELLES, H. L. Direito administrativo brasileiro. 20. ed. São Paulo: Malheiros, 1995.

PNEF (PROGRAMA NACIONAL DE EDUCAÇÃO FISCAL). Convite à cidadania, versão n. 8. Escola de Administração Fazendária e Secretaria Executiva do Grupo de Trabalho Educação Fiscal. Brasília, 2002.

REA, L. M.; PARKER, R. A. Metodologia de pesquisa: do planejamento à execução. São Paulo: Pioneira, 2000.

RIO GRANDE DO SUL (Estado). Lei $\mathrm{n}^{\mathrm{o}}$ 10.045, de 29 de dezembro de 1993. Estabelece tratamento diferenciado às microempresas, aos microprodutores rurais e às empresas de pequeno porte e dá outras providências. 1993. Disponível em: <www.al.rs.gov.br/legiscomp/arquivo. asp?Rotulo=Lei\%20n\%2010045\&idNorma=16\&tipo=pdf $>$. Acesso em: 20 out. 2006.

ROSSETTI, J. P. Introdução à economia. 16. ed. São Paulo: Atlas, 1994.

RUA, M. G. Estado, governo e administração pública. Brasília: Esaf., 2000. texto não publicado.

SOUSA, R. G. Compêndio de legislação tributária. São Paulo: Resenha Tributária, 1975.

Rap Rio de Janeiro 40(5):841-64, Set./Out. 2006 